\title{
Author Correction: FAN1 interaction with ubiquitylated PCNA alleviates replication stress and preserves genomic integrity independently of BRCA2
}

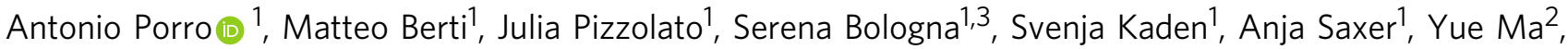 \\ Kazuo Nagasawa ${ }^{2}$, Alessandro A. Sartori (i) ${ }^{1} \&$ Josef Jiricny ${ }^{1,4}$
}

Nature Communications 8:1073 10.1038/s41467-017-001074-6; Article published online: 20 October 2017

The financial support for this Article was not fully acknowledged. The Acknowledgements should have included the following:

This study was in part supported by the Swiss National Foundation Grant No.: 31003A-156023 to Alessandro Sartori.

Published online: 21 December 2017

\begin{abstract}
(c) Open Access This article is licensed under a Creative Commons Attribution 4.0 International License, which permits use, sharing, adaptation, distribution and reproduction in any medium or format, as long as you give appropriate credit to the original author(s) and the source, provide a link to the Creative Commons license, and indicate if changes were made. The images or other third party material in this article are included in the article's Creative Commons license, unless indicated otherwise in a credit line to the material. If material is not included in the article's Creative Commons license and your intended use is not permitted by statutory regulation or exceeds the permitted use, you will need to obtain permission directly from the copyright holder. To view a copy of this license, visit http://creativecommons.org/licenses/by/4.0/.
\end{abstract}

(C) The Author(s) 2017

\footnotetext{
${ }^{1}$ Institute of Molecular Cancer Research of the University of Zurich and ETH Zurich, Winterthurerstrasse 190, CH-8057 Zurich, Switzerland. ${ }^{2}$ Department of Biotechnology and Life Science, Tokyo University of Agriculture and Technology, 2-24-16 Naka-cho, Koganei-shi, Tokyo 184-8588, Japan. ${ }^{3}$ Wellcome Trust/ Cancer Research UK Gurdon Institute, Tennis Court Road, Cambridge CB2 1QN, UK. ${ }^{4}$ Present address: Institute of Molecular Life Sciences of the University of Zurich and Institute of Biochemistry of the ETH Zurich, Otto-Stern-Weg 3, Zurich 8093, Switzerland. Antonio Porro, Alessandro A. Sartori and Josef Jiricny contributed equally to this work. Correspondence and requests for materials should be addressed to A.P. (email: porro@imcr.uzh.ch)

or to A.A.S. (email: sartori@imcr.uzh.ch) or to J.J. (email: jjiricny@ethz.ch)
} 